\title{
Putting the Conversation about Gun Ownership and Safety in Context
}

\author{
Wayne Shelton, $\mathrm{PhD}$
}

Alden March Bioethics Institute, Albany Medical College, Albany, NY, USA.

J Gen Intern Med 31(10):1113-4

DOI: $10.1007 / \mathrm{s} 11606-016-3739-6$

(c) Society of General Internal Medicine 2016

I this issue of JGIM, Brendan Parent presents the relevant 1 facts about the risks of gun ownership, and makes it clear that physicians can have a beneficial role in educating patients and their families about these risks, without violating their rights to privacy and to own guns. ${ }^{1}$ In order to avoid jeopardizing "the patient's trust in the physician," physicians should broach the topic of gun ownership in a "manner least likely to create offense"; thus, he or she attempts to craft recommendations that "promote neutrality, privacy, and respect." It is hard to disagree much with his sensible-sounding recommendations. However, my concern with this piece is that it does not go far enough in describing the current contentious cultural and political context of gun ownership in the United States. In such a context, physicians' efforts to have conversations about gun ownership and safety are seriously imperiled.

For the past 30 years, the National Rifle Association (NRA) has waged an intense, ideologically driven, public crusade to promote expansive rights to own and carry guns in all parts of public life, including churches, schools, airports, and bars. Their efforts have been resisted by a variety of voices on the other side that favor a mix of gun regulations. The resulting debate has been intensified by the numerous incidents of gun violence across the country since the Sandy Hook tragedy. https://everytownresearch. org/school-shootings/ Gun rights advocates continue to ratchet up the call for expansive gun ownership, claiming that the public, wherever they may be, must be prepared, armed and ready to defend themselves with deadly force, or as Wayne LaPierre proclaimed, "the only way to stop a bad guy with a gun is a good guy with a gun." They assume, contrary to considerable empirical evidence, that individual citizens, their families, and those around them in public places are safer if they carry a gun. Those opposed to this position, though not necessarily against gun ownership, favor gun registration and background checks, including for sales of guns at gun shows, which are seen by the NRA as direct threats to Second Amendment rights. This debate, which continues at a fevered pitch, is the context in which physicians are expected to have rational conversations with their patients, based on empirical evidence, not personal opinions.

Published online May 16, 2016
How does a physician meaningfully serve as an evidencebased healthcare expert in such a setting? The current evidence suggests that the lives of many individuals are at risk due to misguided or plainly false information perpetuated by a staunchly defiant gun lobby that tends to disregard, deny, or block empirical research. These are the individuals - when they become patients - whom physicians are obligated to ask if they are willing to discuss gun ownership and safety. Though there is some evidence (as Parent suggests) that physician-initiated gun conversations may have positive effects, more robust evidence is needed to determine the likelihood that patients would agree to have this conversation, especially in parts of the country with high gun ownership rates, and the willingness of physicians to even ask the question. Moreover, among patients who agree to have the conversation, we need to know the real effects of physicians fulfilling this obligation, and learn more about how physicians can more effectively inform patients of the scientific evidence regarding guns (such as it exists). At present, there is arguably sufficient data available $e^{2,3}$ to provide an adequate assessment of the risks of gun ownership in terms of increased risk of suicide, homicide, and accidental death. However, through the successful lobbying efforts of the NRA, Congress has for the past 20 years blocked further public data collection by the Centers for Disease Control and Prevention on gun ownership and violence. The limited available evidence, compiled primarily by a handful of universities, and the lack of highquality national data not only hampers physicians' efforts to fulfill their professional roles; it also keeps the public from accessing sound health-related information about the risks of gun ownership. Greater availability of high-quality, data-driven information on gun ownership and violent injury could also make conversations with physicians more likely to succeed in the first place.

Though physicians, as well as legislators and policymakers, would be better able to perform their jobs by having data that would inform them about issues such the most effective ways to prevent suicide, reduce homicides, and increase effective safety methods, especially those that will protect children, the broader patterns of risk associated with guns is evident; over a half-million people have died by firearms during the past 20 years, currently about 33,000 each year. http://www. huffingtonpost.com/entry/dickey-amendment-gun-violenceresearch-ban_us_56606201e4b072e9d1c4eaaa

We know that many patients keep guns in their homes, placing themselves and their families at additional risk of 
injury and death, particularly suicide. For this reason, many physicians oppose keeping guns in the home. However, a physician's personal beliefs about having guns in the home are likely informed by evidence of the additional health risks, which the physician understands at a professional level. As health professionals, physicians should no more judge or criticize patients for owning guns than for any other type of unhealthy behavior. But, assuming the patient has agreed to answer questions and discuss gun ownership, it is appropriate to present the facts about the inherent risks of gun ownership. It is not surprising that many physicians are against guns in the home, in the very same way they object to many other unhealthy behaviors. The thrust of being a good professional is calmly and compassionately describing the evidence-based risks associated with gun ownership and, as in all cases of risky patient behaviors and habits, avoiding being personally offensive to the patient.

On the surface, it may be clear how a physician should fulfill their professional obligations to broach and discuss the risks of gun ownership with patients. But below the surface, the context in which these discussions occur complicates matters. This is why it is also important for physicians to remember that, regardless of their effectiveness in their encounters with patients, they also have a professional obligation - not alluded to in Parent's article - to work for systemic change and progress, including "...through their professional societies, to advocate for national, state, and local efforts to enact legislation to implement evidence-based policies...to reduce the risk of preventable injuries and deaths from firearms, including but not limited to universal background checks." ${ }^{4}$ Physician involvement at the policy level is also important in terms of the possible health benefits to patients, and deserves greater attention.

Corresponding Author: Wayne Shelton, PhD; Alden March Bioethics InstituteAlbany Medical College, Albany, NY, USA (e-mail: sheltow@mail.amc.edu).

Compliance with Ethical Standards:

Conflict of Interest: The author reports no conflicts of interests.

\section{REFERENCES}

1. Parent, B. Physicians asking patients about guns: Promoting patient safety, respecting patient rights. J Gen Intern Med. doi:10.1007/s11606-0163694-2.

2. Kellermann AL, Rivara FP, Somes G, Reay DT, Francisco J, Banton JG, Prodzinski J, Fligner C, Hackman BB. Suicide in the home in relation to gun ownership. NEJM. 1992;327(7):467-72.

3. Kellermann AL, Rivara FP, Rushforth NB, Banton JG, Reay DT, Francisco JT, Locci AB, Prodzinski J, Hackman BB, Somes G. Gun ownership as a risk factor for homicide in the home. N Engl $\mathrm{J}$ Med. 1993;329: 1084-1091.

4. Butkus R, Doherty R, Daniel H. Reducing firearm-related injuries and deaths in the United States: executive summary of a policy position paper from the American College of Physicians. Ann Intern Med. 2014;160(12):858-79. 